\title{
EFEITO DO TAMANHO DE SÉRIES HISTÓRICAS NA DEMANDA DE IRRIGAÇÃO DO PERÍMETRO IRRIGADO DO GORUTUBA, MG
}

\author{
Daniel Fonseca de Carvalho ${ }^{1}$, Débora Candeias Marques $^{2}$, Expedito José Ferreira ${ }^{3}$ \& \\ Luiz Fernando Coutinho de Oliveira ${ }^{4}$
}

\begin{abstract}
RESUMO
Este trabalho foi desenvolvido com o objetivo de se estudar a influência do número de anos da série histórica de dados climáticos no volume de água para irrigação, no perímetro irrigado do Gorutuba. Utilizando-se um aplicativo desenvolvido em ambiente Windows 95, em linguagem DELPHI, foram estudadas três situações de séries históricas e, para cada uma, o volume de água estimado foi comparado com o volume derivado no perímetro para o ano de 1996, em que os resultados mostraram que: utilizando-se a série histórica de 1984-1994, os volumes de água estimados foram, em média, $16,2 \%$ por mês, inferiores àqueles estimados, empregando-os com a série 1984-1998, e de 53,8\% por mês, inferiores aos volumes estimados utilizando-se os dados climáticos de 1996, e que o número de anos da série histórica de dados climáticos pode influenciar decisivamente na estimativa do volume de água para irrigação.
\end{abstract}

Palavras-chave: precipitação dependente, evapotranspiração, demanda de irrigação, perímetro irrigado

\section{EFFECT OF THE SIZE OF HISTORIC SERIES ON DEMAND OF WATER IN GORUTUBA IRRIGATION DISTRICT, MINAS GERAIS, BRAZIL}

\begin{abstract}
With the objective of studying the effect of the size of different historic series of climatic data in the volume of water, in the Gorutuba Irrigation District, a computer model and three historic series with different sizes were considered. For each one, the volume of water was simulated and was compared with the volume of water measured in the year of 1996. The results showed that using a historical series of 1984-1994, the volumes of water were lower $16.2 \%$ per month than based on $1984-98$, and $53.8 \%$ per month with regard to estimated on data of 1996 , and that the number of years of historic series may have strong influence on the estimation of the irrigation water volume.
\end{abstract}

Key words: dependable precipitation, evapotranspiration, irrigation demand, irrigation district

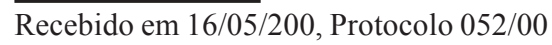

${ }^{1}$ Prof. Adjunto, Departamento de Engenharia-UFRRJ, CEP 23851 - 970, Seropédica, RJ. Fone: (0xx21) 6821865. E-mail: carvalho@ufrrj.br

${ }^{2}$ Estudante de Agronomia, UFRRJ, Seropédica, RJ

${ }^{3}$ Doutor em Engenharia Agrícola. CODEVASF - Montes Claros. Fone: (0xx38) 2210620

${ }^{4}$ Prof. Adjunto. Faculdade de Agronomia, UFG, CEP 74001 - 970, Goiânia, Fone: (0xx62) 821 1537, Fax: (0xx62) 2051099. E-mail: lfco@agro.ufg.br 


\section{INTRODUÇÃO}

Em decorrência da instabilidade climática, a maior parte do nordeste brasileiro, incluindo algumas regiões do Estado de Minas Gerais, mostra um dramático quadro de destruição de lavouras, desemprego e fome. Nos últimos anos, as secas foram responsáveis por uma redução da ordem de $9 \%$ no produto da agropecuária regional, e de 4,5\% no PIB; a população atingida chegou a quase 12 milhões e o número de trabalhadores inscritos nas frentes emergenciais de trabalho, a 2 milhões (ANEEL, 1999).

Uma alternativa para minimizar o problema é fazer uso da técnica de irrigação, que tem, como principal objetivo, suprir as necessidades de água das plantas, possibilitando aumento expressivo da produtividade e da demanda de mão-de-obra, com a fixação do homem no meio rural, diminuição do risco de investimento em virtude do uso de uma agricultura com nível tecnológico mais elevado, além de permitir maior eficiência no uso de fertilizantes e tornar possível à introdução de culturas de maior valor econômico (Bernardo, 1992).

A partir dos anos 80, a irrigação passou a ser uma tecnologia amplamente utilizada e a sua adoção vem crescendo de forma acelerada. Objetivando, entre outras metas, atender à demanda de recursos e tecnologia para a agricultura irrigada, os governos federal e estaduais criaram diversos perímetros irrigados, além de vários programas que contemplam a execução de obras de saneamento ambiental, controle de enchentes e recuperação de vales e, ainda, o programa de desenvolvimento da agroindústria, que visa ao aproveitamento de matérias-primas originadas de sistemas agrícolas irrigados, entre outros.

Os perímetros irrigados, compostos, em sua maioria, por sistemas coletivos, compreendem as áreas e instalações necessárias ao desenvolvimento racional da agricultura irrigada, incluindo toda a infra-estrutura necessária à captação, bombeamento, adução, distribuição e aplicação de água às áreas irrigadas, desenvolvimento, adequação e melhoramento das terras, armazenamento de insumos e produtos agrícolas, comercialização, moradia e bem-estar social dos agricultores e seus dependentes, etc. (Scaloppi, 1988).

$\mathrm{O}$ fornecimento da água de irrigação no momento adequado e de maneira eficiente, constitui uma das principais metas das companhias que gerenciam os perímetros irrigados em todo o mundo. De acordo com Loftis \& Houghtalen (1987) a execução desta tarefa é sempre difícil, mesmo em áreas onde o volume de água disponível é adequado, sendo que o sucesso desta prática depende do alto nível de manejo do sistema de distribuição de água.

Os principais fatores que influenciam na quantidade de água requerida pelas plantas, são os climáticos, as características das plantas, as práticas culturais e o tipo de solo, sendo as principais técnicas para estimar o requerimento de água pelas plantas, baseadas em dados climáticos (Sediyama, 1996). Portanto, é de extrema importância a obtenção de dados climáticos regionais confiáveis, visando às estimativas mais precisas da evapotranspiração e ao melhor aproveitamento das precipitações naturais no dimensionamento de sistemas de irrigação; entretanto, a intensa queima de combustíveis fósseis e das florestas, tem contribuído para o aumento da quantidade de gás carbônico presente na atmosfera, favorecendo uma alteração no clima, principalmente com o aumento da temperatura média na superfície terrestre. Como conseqüência deste contínuo aquecimento global, já é possível verificar-se, em algumas regiões, diversas alterações climáticas que têm contribuído para uma mudança nas técnicas de plantio de certas culturas, em função da alteração do regime pluviométrico. Desta forma, o plantio dessas culturas se tornará difícil, ou mesmo impossível, em muitas das áreas onde elas crescem atualmente (EMBRAPA,1996).

Tendo em vista a importância climática na estimativa do consumo de água pelas culturas, desenvolveu-se este trabalho com o objetivo de se comparar a demanda de irrigação estimada por diferentes tamanhos de séries históricas com aquela derivada no ano de 1996, no perímetro irrigado do Gorutuba.

\section{MATERIAL E MÉTODOS}

Para a execução deste trabalho foram utilizados dados do perímetro irrigado do Gorutuba, localizado na região norte do Estado de Minas Gerais. Com uma área total de 11.280 ha, o projeto Gorutuba possui $127,5 \mathrm{~km}$ de canal, sendo $24,5 \mathrm{~km}$ de canal principal e 103,0 km de canais secundários. A rede de canais é dividida em 17 redes de acéquias, que abastecem 4.780 ha irrigáveis (CODEVASF, 1996). Para fins de comparação, os dados de demanda de irrigação foram estimados para todo o perímetro, considerando-se três situações: a) série histórica de 1984 a 1994, conforme Carvalho et al. (1999); b) série histórica de 1984 a 1998; e c) considerando-se apenas dados de 1996, ano de análise deste trabalho. Vale dizer que o ano de 1996 foi escolhido em função da disponibilidade de dados referentes ao projeto e que, inicialmente, a única série histórica disponível era aquela referente a 1984 a 1994. Posteriormente à realização desse estudo, dados climáticos mais recentes foram conseguidos junto a CODEVASF, o que motivou a realização do presente trabalho.

O clima da região foi classificado, segundo Köppen, como Tropical úmido (Chuvoso de savana), Awi: todos os meses do ano com temperatura média acima de $18^{\circ} \mathrm{C}$, temperatura média do mês mais quente acima de $22^{\circ} \mathrm{C}$, temperatura média do mês mais quente menos a temperatura média do mês mais frio $\leq 5$ (Costa, 1994).

A Tabela 1 apresenta os dados climáticos médios para o ano de realização deste trabalho (1996) para a série histórica de 1984 a 1994 e para a série 1984 a 1998. Com exceção dos meses de abril, outubro e novembro, a lâmina mensal precipitada no ano de 1996 foi inferior à lâmina média mensal no período de 1984 a 1994, apresentando lâmina precipitada igual a zero para os meses junho, julho e agosto. Associada à precipitação, a umidade relativa do ar foi inferior em todos os meses do ano de 1996, com exceção do mês de novembro. Considerando-se a série histórica 1984-1998, pode-se perceber que a lâmina precipitada mensal foi também superior à do ano de 1996, no mesmo período. Comparando-se as duas séries históricas, é possível verificar-se que as maiores diferenças na precipitação média são observadas nos meses de janeiro, novembro e dezembro. 
Tabela 1. Dados de insolação (I), precipitação (P), temperatura média (TM) e umidade relativa do ar (UR) na estação INMET 83395 (município de Nova Porteirinha) para o ano de 1996 e para as séries históricas consideradas

\begin{tabular}{|c|c|c|c|c|}
\hline Mês & $\mathrm{I}(\mathrm{h})$ & $\mathrm{P}(\mathrm{mm})$ & $\mathrm{TM}\left({ }^{\circ} \mathrm{C}\right)$ & UR (\%) \\
\hline \multicolumn{5}{|c|}{ A. Dados climáticos para ano de 1996} \\
\hline Janeiro & 9,8 & 9,4 & 26,8 & 65,3 \\
\hline Fevereiro & 9,3 & 41,1 & 27,7 & 61,0 \\
\hline Março & 8,3 & 75,9 & 28,2 & 66,0 \\
\hline Abril & 8,3 & 51,0 & 26,4 & 59,3 \\
\hline Maio & 9,1 & 2,4 & 26,5 & 55,0 \\
\hline Junho & 8,8 & 0,0 & 23,6 & 55,4 \\
\hline Julho & 9,0 & 0,0 & 22,0 & 52,3 \\
\hline Agosto & 8,9 & 0,0 & 24,8 & 51,7 \\
\hline Setembro & 9,1 & 8,8 & 26,5 & 49,3 \\
\hline Outubro & 7,4 & 102,4 & 26,9 & 55,7 \\
\hline Novembro & 5,5 & 295,6 & 25,8 & 71,3 \\
\hline Dezembro & 4,9 & 82,9 & 27,0 & 71,0 \\
\hline \multicolumn{5}{|c|}{ B. Dados climáticos médios para a série $1984-1994$} \\
\hline Janeiro & 7,6 & 136,6 & 26,5 & 74,6 \\
\hline Fevereiro & 8,5 & 60,4 & 27,4 & 70,2 \\
\hline Março & 7,8 & 115,1 & 26,6 & 74,4 \\
\hline Abril & 8,6 & 30,4 & 26,0 & 71,5 \\
\hline Maio & 9,0 & 10,4 & 25,0 & 68,3 \\
\hline Junho & 8,8 & 2,4 & 23,5 & 66,1 \\
\hline Julho & 9,3 & 1,3 & 22,9 & 62,7 \\
\hline Agosto & 9,0 & 3,3 & 24,1 & 58,2 \\
\hline Setembro & 7,8 & 22,1 & 25,8 & 58,5 \\
\hline Outubro & 7,5 & 55,8 & 27,3 & 58,5 \\
\hline Novembro & 5,9 & 146,4 & 26,6 & 70,6 \\
\hline Dezembro & 5,1 & 259,4 & 25,7 & 80,1 \\
\hline \multicolumn{5}{|c|}{ C. Dados climáticos médios para a série $1984-1998$} \\
\hline Janeiro & 8,2 & 87,8 & 26,9 & 67,4 \\
\hline Fevereiro & 8,2 & 79,8 & 27,3 & 66,5 \\
\hline Março & 7,6 & 114,6 & 27,2 & 69,0 \\
\hline Abril & 8,1 & 36,7 & 26,6 & 64,2 \\
\hline Maio & 8,9 & 4,4 & 25,2 & 60,0 \\
\hline Junho & 8,8 & 12,2 & 22,6 & 57,3 \\
\hline Julho & 9,4 & 1,0 & 23,6 & 52,0 \\
\hline Agosto & 9,4 & 3,3 & 24,4 & 47,0 \\
\hline Setembro & 8,8 & 13,1 & 26,6 & 47,0 \\
\hline Outubro & 7,8 & 65,9 & 27,2 & 53,1 \\
\hline Novembro & 5,9 & 226,3 & 26,4 & 66,2 \\
\hline Dezembro & 5,8 & 174,0 & 26,3 & 69,4 \\
\hline
\end{tabular}

A fim de se estimar o consumo de água para irrigação no projeto Gorutuba, foi desenvolvido um programa computacional em ambiente Windows 95, utilizando-se o software DELPHI, apresentado com detalhes por Carvalho (1998). Para fins de planejamento da irrigação, foram determinadas a precipitação dependente e a lâmina de evapotranspiração, variáveis fundamentais no estudo do balanço de água no solo. Na estimativa da lâmina de precipitação dependente, definida como sendo a precipitação que tem determinado nível de probabilidade de ocorrência (normalmente 75\%), utilizou-se a distribuição gama de probabilidade (Assis, 1993) ajustada aos dados diários de precipitação da estação 83395 do INMET, localizada no Centro Regional de Pesquisa do Norte de Minas, da Empresa de Pesquisa Agropecuária de Minas Gerais (CRNM - EPAMIG) município de Nova Porteirinha (MG) com coordenadas geográficas de $15^{\circ} 47^{\prime}$ de latitude Sul, $43^{\circ} 18^{\prime}$ de longitude Oeste e altitude de $516 \mathrm{~m}$.
Para os diferentes tamanhos de série histórica, os dados de precipitação foram agrupados em intervalos de 5 dias, ao longo de todo o ano, seguindo a metodologia utilizada por Assis (1993). Com isto, a distribuição gama foi utilizada para estimar a precipitação dependente, a nível de $75 \%$ de probabilidade, em função das alturas médias pentadiais de precipitação dos dias chuvosos, conforme Sediyama et al. (1996). Para o ano de 1996, como não é possível utilizar-se a distribuição gama de probabilidade, na estimativa da demanda suplementar de irrigação foi considerada a própria lâmina de precipitação ocorrida.

Para todas as situações consideradas, a evapotranspiração de referência (ETo) foi estimada utilizando-se a equação de Penman - Monteith, padrão FAO (Smith, 1991). O balanço de água no solo foi calculado tendo-se como referência a capacidade de campo. A evapotranspiração real das culturas (ETrc) foi calculada multiplicando-se a ETo pelos coeficientes kc (cultura) e ks (coeficiente de umidade do solo) (Bernardo, 1995). Consideram-se os mesmos dados referentes a kc, fator de disponibilidade (f), características físico-hídricas dos solos, culturas implantadas e eficiência de aplicação dos sistemas de irrigação adotados por Carvalho (1998).

No programa computacional desenvolvido é possível simular-se duas condições de operação: contínua e rotativa. Neste trabalho foi utilizado, para todas as situações, o sistema rotativo, que se caracteriza pela determinação do turno de rega que satisfaz ao critério da umidade do solo, não lhe permitindo atingir um valor inferior à umidade mínima recomendada para cada cultura, em todos os lotes alimentados por cada acéquia. O programa simula o ciclo de cada cultura, fazendo o balanço de água no solo, armazenando sempre o menor turno de rega, ou seja, o menor período entre irrigações, a fim de não proporcionar um déficit de água no solo superior àquele permitido para a cultura em questão.

\section{RESULTADOS E DISCUSSÃO}

A Figura 1 apresenta a variação anual da evapotranspiração de referência (ETo) e a precipitação dependente, em nível de $75 \%$ de probabilidade, estimada para períodos pentadiais, para as duas séries históricas consideradas. Com relação à lâmina evapotranspirométrica, não se percebe diferença entre as duas séries de dados mas, analisando-se a lâmina de precipitação dependente, percebe-se uma grande variação nos dados simulados com as diferentes séries históricas. Considerando-se a maior série (1984-1998), a lâmina provável de precipitação é sensivelmente inferior àquela simulada com os dados de 1984-1994, principalmente nos meses de janeiro a dezembro, os quais apresentam, em média, maiores valores de ETo. Pela Figura 1 pode-se notar, ainda, que para a série 1984-1994, com exceção de alguns dias dos meses de janeiro e dezembro, a lâmina evapotranspirada excede a precipitação dependente, evidenciando a necessidade de irrigação para o bom desenvolvimento dos cultivos em todos os meses do ano; para a série 1984-1998, este comportamento foi verificado com menor intensidade apenas no mês de dezembro. 


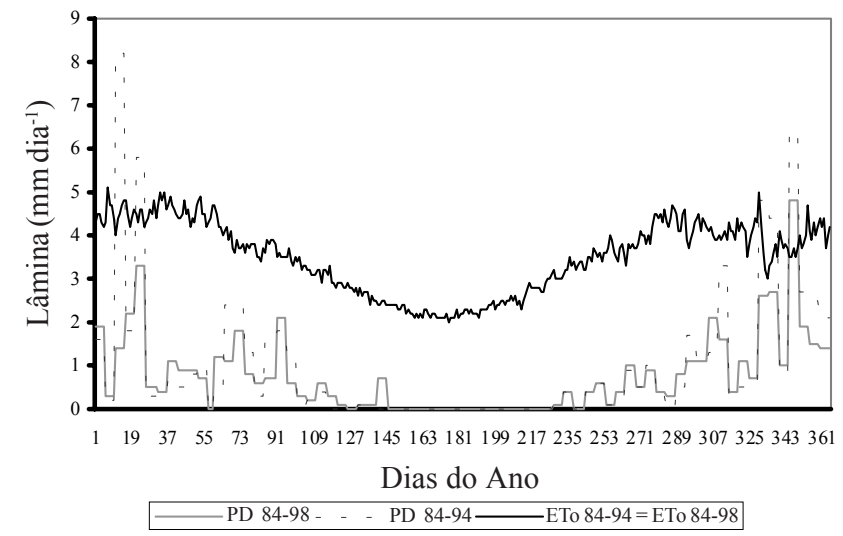

Figura 1. Precipitação dependente e evapotranspiração de referência, estimadas com as séries históricas de 1984 a 1994 e de 1984 a 1998
A Figura 2 apresenta os volumes de água para cada acéquia, simulados para as condições de irrigação total e suplementar, nos meses de janeiro (época chuvosa) e julho (época seca) respectivamente. É possível verificar-se que, para o mês de janeiro, os volumes de água estimados, considerando-se a contribuição da precipitação dependente (irrigação suplementar) é inferior àqueles simulados com irrigação total, comportamento este explicado pela maior lâmina de precipitação ocorrida nesta época do ano; efeito oposto é verificado no mês de julho (Figura 2B) quando o índice pluviométrico é muito baixo e/ou inexistente na região (Tabela 1). Nesta condição, os volumes estimados, considerando-se irrigação contínua e suplementar, não diferem acentuadamente para as três situações estudadas.

Analisando o volume de água estimado e se considerando os dados climáticos do ano de 1996, percebe-se apenas uma

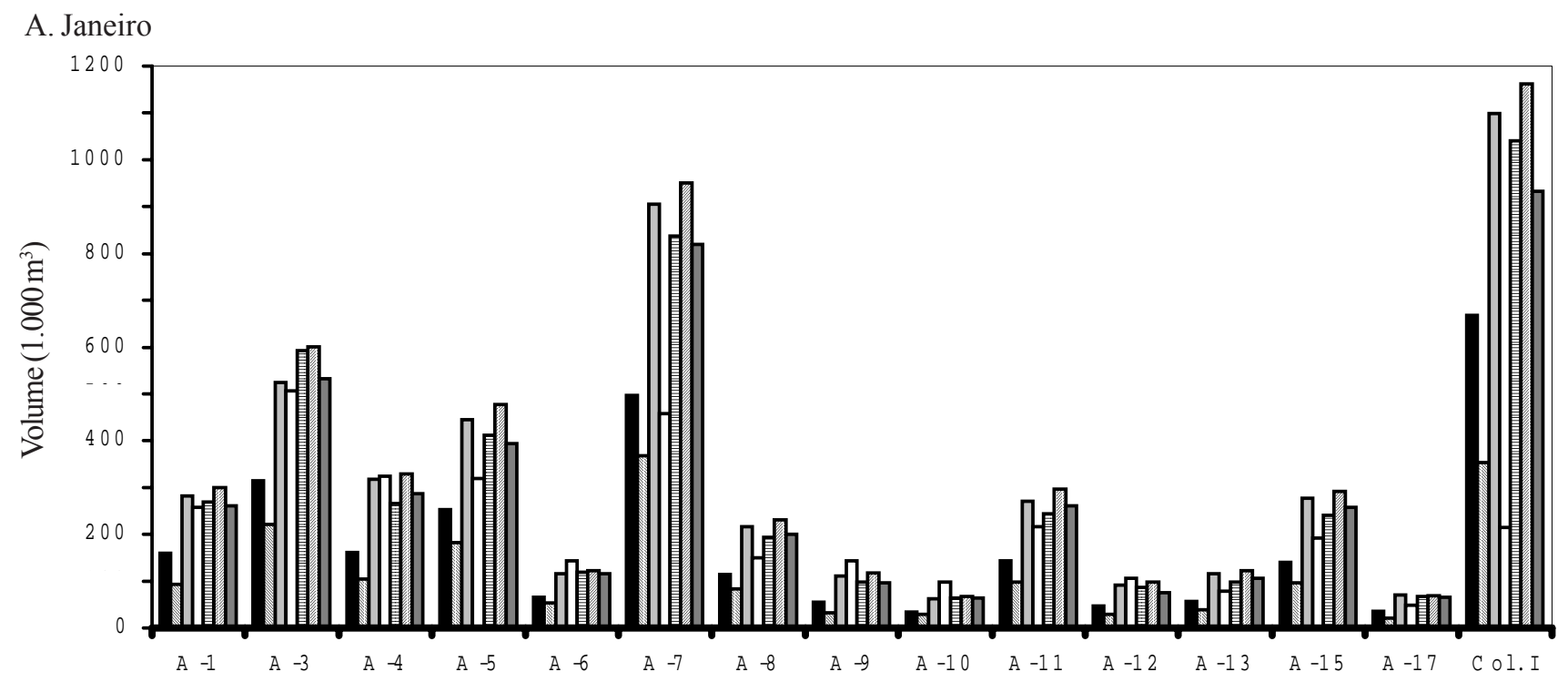

B. Julho

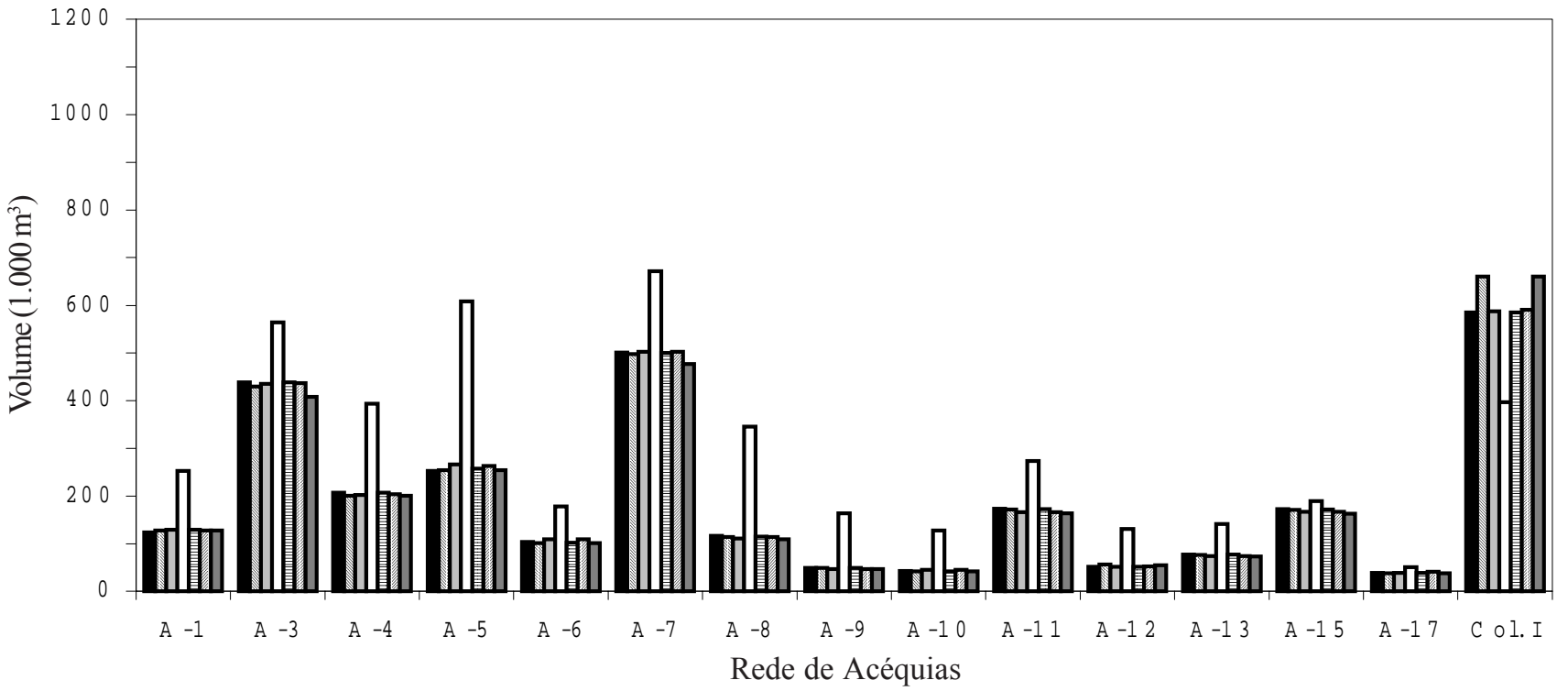

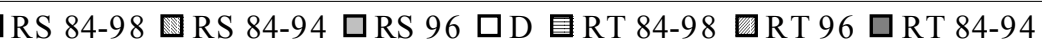

Figura 2. Volume de água $\left(1000 \mathrm{~m}^{3}\right)$ simulado, por acéquia, para fornecimento rotativo com irrigação suplementar (RS) e total (RT) considerando-se séries históricas de 1984-1998 e 1984-1994 e para os dados climáticos do ano de 1996, e volume derivado (D) para o perímetro Gorutuba, nos meses de janeiro (A) e julho (B) 
ligeira superioridade, quando se considerou a irrigação total em relação à suplementar porque, para o ano de 1996, a lâmina de precipitação dependente não foi estimada pela distribuição gama e, sim, considerada àquela que realmente se precipitou. Para as demais situações, as diferenças no volume estimado foram mais acentuadas.

Os volumes de água estimados para o ano de 1996 são superiores aos volumes estimados considerando-se as séries históricas (conforme os dados da Tabela 1) para irrigação total e suplementar. Com relação aos volumes estimados para as duas séries históricas, percebe-se que, considerando-se irrigação suplementar, a série histórica 1984-1998 apresenta maiores valores quando comparada com a série 1984-1994 (Figura 2A). Este resultado pode ter sido influenciado pela própria presença dos dados de 1996, na maior série. Como se constata, neste ano o índice pluviométrico foi bastante atípico em relação aos dados

Tabela 2. Diferenças percentuais entre os volumes de água estimados, em $1000 \mathrm{~m}^{3}$ utilizando-se a série 1984-1994 e os volumes estimados para a série 1984-1998 (A), utilizando-se a série 1984-1994 e os volumes estimados com dados climáticos de 1996 (B) e derivados e volumes de água estimados utilizando-se os dados climáticos de 1996 (C), considerando-se fornecimento rotativo e irrigação suplementar

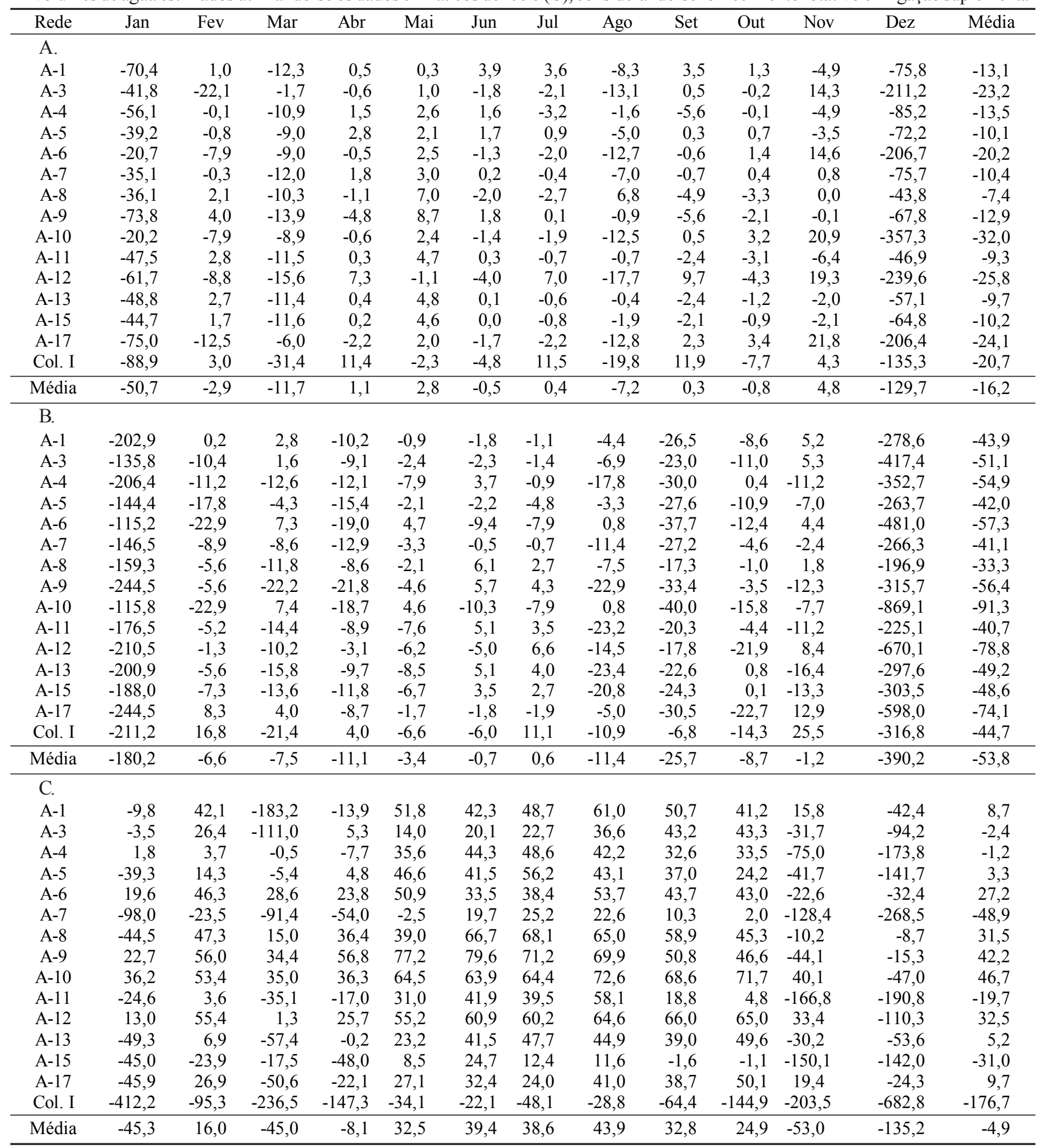


médios apresentados para as séries históricas; com relação à irrigação total, este comportamento se manteve para algumas acéquias, porém com menor intensidade, mas para as acéquias A-4, A-8, A-11, A-13 e A-15, percebe-se menor volume de água estimado quando se considerou a maior série histórica. Este fenômeno pode ser explicado por uma característica própria de elaboração do programa computacional, o qual totaliza, mensalmente, os volumes de água para cada lote irrigado por determinada acéquia. Em função do tipo de solo e das culturas implantadas, diferentes turnos de rega são adotados, fazendo com que, nestas situações, os volumes de água estimados no final do mês de janeiro fossem possivelmente computados no mês de fevereiro; entretanto, analisando-se a Figura 2A, percebe-se que, ao se considerar uma série histórica maior de dados climáticos, maiores volumes de água foram estimados para o perímetro irrigado do Gorutuba, no mês de janeiro.

Quanto ao volume derivado em relação aos volumes estimados, o mesmo comportamento foi obtido por Carvalho (1998) com exceção do ano de 1996. Como já foi dito, para a realização deste trabalho foram considerados os dados de cultura e sistemas de irrigação observados para esse ano, porém, observando-se a Figura 2A, é possível constatar-se que os volumes de água estimados para o mês de janeiro com os dados climáticos de 1996, estão relativamente próximos aos volumes derivados para cada acéquia, com exceção dos lotes irrigados pela acéquia A-7 e aqueles localizados na Colonização I. Nessas duas acéquias, um grande número de lotes localiza-se nas margens de drenos coletores e de pequenos córregos e são irrigados com água dos mesmos, utilizando bombeamento próprio, não se necessitando de água proveniente do canal; entretanto, analisando-se o mês de julho percebe-se, na Figura 2B, que apenas na Colonização I o volume derivado foi inferior aos estimados pelo programa. Nesta colonização, além do problema mencionado anteriormente, o fornecimento de água foi afetado pelas obras de reabilitação do projeto, entre elas a recuperação do leito e a elevação das bordas do canal principal.

A Tabela 2A apresenta as diferenças percentuais entre os volumes de água estimados quando se considerou a série 1984-1994, em relação aos dados obtidos, utilizando-se a série 1984-1998. O sinal negativo indica que, na maior parte do ano e na maioria das acéquias, ao se considerar a menor série histórica (1984-1994) os volumes de água simulados foram subestimados com relação àqueles estimados, utilizando-se a série 1984-1998. Essa subestimativa foi, em média, de $16,2 \%$ por mês que, em termos de volume de água, significa que houve uma subestimativa de 155.201,8 $\mathrm{m}^{3}$, no ano de 1996.

Análise semelhante foi realizada a fim de se comparar os volumes de água estimados, utilizando-se a série 1984-1994 e os dados climáticos de 1996. Os dados da Tabela 2B confirmam aqueles apresentados na Tabela 1, indicando que a demanda de água estimada para o ano de 1996 foi superior em 53,8\% por mês, em média, àquela estimada considerando-se a série 1984-1994. Quanto ao volume de água, pode-se dizer que a superestimativa foi da ordem de $494.290,4 \mathrm{~m}^{3}$, para o ano de 1996.

A Tabela $2 \mathrm{C}$ apresenta uma análise semelhante às anteriores, realizada entre o volume de água derivado no ano de $1996 \mathrm{e}$ aquele estimado apenas com os dados climáticos de 1996. Pode-se perceber comportamento distinto em relação as Tabela 2 e 3.
Nesta Tabela percebe-se que, apesar de em alguns meses e para algumas acéquias o volume derivado ter sido superior ao estimado, em termos médios globais, o volume de água derivado para o perímetro foi menor $4,9 \%$, em relação àquele estimado com os dados climáticos de 1996, considerando-se irrigação suplementar e fornecimento rotativo de água, ou seja, para o ano de 1996 o volume de água derivado para o projeto não foi tão superior ao estimado, como concluído por Carvalho (1998) que se baseou na série 1984-1994, indicando que o manejo de água no perímetro do Gorutuba não está tão ineficiente quanto parece.

\section{CONCLUSÕES}

Com base nos resultados obtidos, pode-se concluir que:

1. Considerando-se a série histórica de 1984-1994, os volumes de água estimados para o perímetro irrigado do Gorutuba, baseados nos planos de cultivo do ano de 1996 foram, em média, $16,2 \%$, por mês, inferiores aqueles estimados para a série $1984-1998$ e de $53,8 \%$, por mês, inferiores aos volumes estimados com os dados climáticos de 1996.

2. Em termos de volume de água, houve uma subestimativa de $155.201,8 \mathrm{~m}^{3}$ e de $494.290,4 \mathrm{~m}^{3}$ para o ano de 1996, quando foi utilizada a série 1984-1994 em relação à série 1984-1998 e aos dados de 1996, respectivamente.

3. Para as condições estudadas, o número de anos da série histórica de dados climáticos influenciou decisivamente na estimativa do volume de água para irrigação.

\section{REFERÊNCIAS BIBLIOGRÁFICAS}

ANEEL, Agência Nacional de Energia Elétrica. O Estado das Águas no Brasil - 1999. Perspectivas de gestão e informação de recursos. Brasília, D. F.: ANEEL, SIH, MMA, SRH, MME. 1999.359p.

ASSIS, F.N. Ajuste da função Gama aos totais semanais de chuva de Pelotas - RS. Revista Brasileira de Agrometeorologia, Piracicaba, v.1, n.1, p.131-136, 1993.

BERNARDO, S. Desenvolvimento e perspectiva da irrigação no Brasil. Revista Engenharia na Agricultura, Viçosa, v.1, n.14, p.1-14, 1992.

BERNARDO, S. Manual de irrigação. 6. ed. Viçosa, MG: UFV, $1995.657 \mathrm{p}$.

CARVALHO, D.F. Otimização do uso da água no perímetro irrigado do Gorutuba. Viçosa, UFV, 1998, 145p. Tese Doutorado

CARVALHO, D.F.; SOARES, A.A.; RIBEIRO, C.A.A.S.; SEDIYAMA, G.C.; PRUSKI, F.F. Otimização do uso da água no perímetro irrigado do Gorutuba, utilizando a técnica da programação linear. In: Congresso Brasileiro de Engenharia Agrícola, 28, 1999, Pelotas. CD Rom

CODEVASF - Companhia de Desenvolvimento do Vale do São Francisco. Relatório anual do perímetro Gorutuba. Brasília, DF, 1996.49p.

COSTA, M.H. Classificação climática. Engenharia na Agricultura, Viçosa, 1994. 12p. Caderno Didático 18

EMBRAPA - Empresa Brasileira de Pesquisa Agropecuária. Atlas do meio ambiente do Brasil. Brasília: Editora Terra Viva, $2^{\mathrm{a}}$ ed., 1996. 160p. 
LOFTIS, J.C.; HOUGHTALEN, R.J. Optimizing temporal water allocation by irrigation ditch companies. Transaction of the ASAE, St. Joseph, v.30, n.4, p.1075-1082, 1987.

SCALOPPI, E.J. Sistemas de irrigação e seus componentes. Brasília, D.F.: ABEAS, 1988. 68p. Curso de Engenharia de Irrigação. Módulo 5.
SEDIYAMA, G.C. Evapotranspiração: Necessidade de água para os cultivos. Brasília, D.F.: ABEAS. 1996. 167p. Curso de Engenharia de Irrigação. Módulo 2

SMITH, M. Report on the expert consultation on revision of FAO methodologies for crop water requeriments. Rome, FAO. 45p. 1991. 